\title{
Monitoring forest dynamics and landslide susceptibility in Mechi- Balason interfluves of Darjiling Himalaya, West Bengal using forest canopy density model (FCDM) and Landslide Susceptibility Index model (LSIM)
}

\author{
Mostafa Jamal $^{1} \cdot$ Sujit Mandal $^{1}$
}

Received: 12 October 2016/ Accepted: 18 October 2016/Published online: 26 October 2016

(C) Springer International Publishing Switzerland 2016

\begin{abstract}
Mapping and monitoring of forest extent is a common requirement of regional forest inventories and public land natural resource management in India. The present study involves the assessment of forest dynamicity using forest canopy density model and the preparation of Landslide Susceptibility Index map using Landslide Susceptibility Index model in Mechi-Balason interfluves of Mirik Block of Darjiling Himalaya to find out the relationship between areal coverage of the forest and landslides. The forest canopy density model and forest pattern map of the study was prepared considering different forest parameter such as Bareness Index, Scaled Shadow Index, NDVI, fractional vegetation cover and forest canopy density on GIS platform. All these parameter were integrated applying Multi Criteria Decision Making Approach and Rank Sum Method to develop regeneration, degeneration and unchanged forest area map of the study area. Finally this forest map was incorporated with landslide susceptibility value to draw a conclusion about the role of forest cover in landslide. It is found that the Landslide Susceptibility Index value is higher in the degenerated portion of the forest and LSI is lower in the regenerated portion of the forest. So it can be concluded that landslide can be one of the major factor of forest dynamicity apart from this the other natural and anthropogenic factors may responsible for the forest dynamicity of the study area.
\end{abstract}

Mostafa Jamal

mostafajamal370@gmail.com

Sujit Mandal

mandalsujit2009@gmail.com

1 Department of Geography, University of Gour Banga, Malda, West Bengal 732103, India
Keywords Forest dynamicity · Forest canopy density · Multi Criteria Decision Making Approach - Landslide Susceptibility Index

\section{Introduction}

Forest cover is of great interest to a variety of scientific and land resource management applications, many of these applications needs not only information on forest categories, but also tree canopy density (Banerjee et al. 2014). The increasing use of satellite Remote Sensing for civilian use has proved to be the most cost effective means of mapping and monitoring environmental changes in terms of vegetation, especially in developing countries (Azizia et al. 2008). The broadest use of remote sensing has been to identify and to map vegetation types (Tucker et al. 1984). Forest canopy cover, also known as canopy coverage or crown cover, is defined as the proportion of the forest floor covered by the vertical projection of the tree crowns (Jennings et al. 1999). Estimation of forest canopy cover has recently become an important part of forest inventories. The canopy closure and the number of the trees per unit area are reduced by the anthropogenic intervention in the natural forest. Satellite remote sensing has played a pivotal role in generating information about forest cover, vegetation type and land use changes (Saeijamalabad and Abkar 2000). The change in the density should be considered for the better management of the forest. Forest canopy density is one of the most useful parameters to consider in the planning and implementation of rehabilitation program. It is possible that there isn't any change in the area of forest during the time but the density of forest canopy is changed (Azizia et al. 2008). Satellite based methods are conventional remote sensing method and biophysical response modelling. Different conventional remote 
sensing method such as slicing, image arithmetic, segmentation and multispectral image classification are prepared by different authors. One of the most complete of these methods is classification. Classification is based on qualitative analysis of information derived from "training areas" (i.e. ground truthing or verification). However, this has certain disadvantages in terms of time and cost requirements for training area establishment. Forest land cover information is often derived from remotely sensed images using classification algorithms (Franklin et al. 1986; Mickelson et al. 1998), many of which require a substantial amount of reference data (Townshend 1992a; Hall et al. 1995). Reliable reference data is also required for assessing classification results. Approaches to map forest canopy density, produced categorical maps with two (Boyd et al. 2002) or more classes (Rikimaru 1996; Rikimaru et al. 2002) rather than a continuous variable. Joshi et al. (2006) argued that canopy density should be treated as a continuous rather than discrete variable.

Vegetation cover plays an important role in causing the landslides in the mountain environment of Darjiling Himalaya. The continuous changes of vegetation cover as result of continuous growth and expansion of human settlement over the mountain slope and the elimination of forest area changes hydro-geomorphic characteristics i.e. surface run-off, soil erosion, sediment yield, infiltration capacity as well as pore-water pressure and cohesion of the slope soil. The changes of hydro-geomorphic characteristics of the slope invite landslides. To assess the role of forest cover in landslide phenomena, the present work attempted to prepare Landslide Susceptibility Index Map. Landslide analysis is mainly done by assessing susceptibility, hazard and risk. Remote Sensing and GIS based landslide hazard zonation approach had been studied by Muthu and Petrou (2007), Caiyan and Jianping (2009), and Mondal and Maiti (2011). Rowbotham and Dudycha (1998), Donati and Turrini (2002), Lee and Choi (2003), Lee et al. (2004a, b), 2007), Pradhan and Lee (2010a, 2010b), Sarkar and Kanungo (2004) and Pandey et al. (2008), have studied and applied the probabilistic model for landslide susceptibility and risk evaluation. Guzzetti et al. (1999) summarized many landslide hazard evaluation studies. Jibson et al. (2000) and Zhou et al. (2002) applied the probabilistic models for landslide risk and hazard analysis. Vijith et al. 2009; Vijith and Madhu 2008) introduced the logistic regression model for landslide hazard mapping. The present study is dealt with the scientific assessment of the ability of IRS imagery for estimating forest canopy cover, the degree of forest disturbance through forest canopy density and to find out relationship between landslide and forest disturbance on GIS of the Mechi-Balason interfluves of Darjiling Himalaya West Bengal.

\section{The study area}

Mirik Block is situated in the interflueves area of the river Mechi and Balasan in Darjeeling Himalaya with the latitude and longitudinal extension of $26^{\circ} 45^{\prime} \mathrm{N}-26^{\circ} 55^{\prime} \mathrm{N}$ and $88^{\circ} 10^{\prime} \mathrm{E}-88^{\circ} 14^{\prime} \mathrm{E}$. The elevation ranges from $400 \mathrm{~m}$ to over $1600 \mathrm{~m}$ in the Mirik Block. The elevation of the block is increases towards north and the highest elevation found near the Helipad point of Mirik town. The whole area is attributed with very steep slope. SH-12 is the main state high way which is constructed modifying the steep slope in the study area and such modification leads to landslide. Lithologically, Mirik Block of Darjiling Himalaya is experienced with sandstone Shale, Slate, Schist, Quartzite, and unclassified Crystalline mainly Schist. The most of the northern part of the block is mainly composed with some unclassified crystalline mainly Schist. In the lower middle portion of the Mirik Block there have not found the dominancy of single lithology (Fig. 1).

\section{Materials and methods}

ETM + imagery 1990, 2001 and IRS, LISS-III-2016 data has been properly used in the present study. The images were geometrically corrected. The control points were selected from common points recognizable on the topographic map. The IRS images were corrected by 30 points using second degree polynomials ( $\mathrm{RMSE}=0.5 \mathrm{pixel}$ ). The pixels were resampled by the nearest neighbour method to maintain their originality. In the present study, a relationship has been drawn between forest dynamicity and landslide susceptibility of Mirik Block to know the degree of forest disturbances and its relation to landslide. The forest disturbance analysis has been done through measuring the disturbances in forest canopy density and the nature of forest itself. The forest disturbance map was prepared combining soil Bareness Index (BI), Shadow Index (SI), NDVI, vegetation density (VD), fractional vegetation cover (FVC) and forest canopy density (FCD). All the parameters were integrated using Multi Criteria Decision Making (MCDM) approach following Satty's Rank Sum method. After assigning the weight to all the parameters a linear regression model was performed to create the forest map for three consecutive years of 1990, 2001 and 2016. To classify the forest in several classes like extremely high, high, high open, Open Shrubs etc. all the forest raster data has been standardized using $\mathrm{Z}$ score and in finally classification process was accomplished. On the other hand a landslide inventory map of Mirik Block was made on the basis of primary data collected from the direct field measurement. On the basis of the landslide inventory map a 

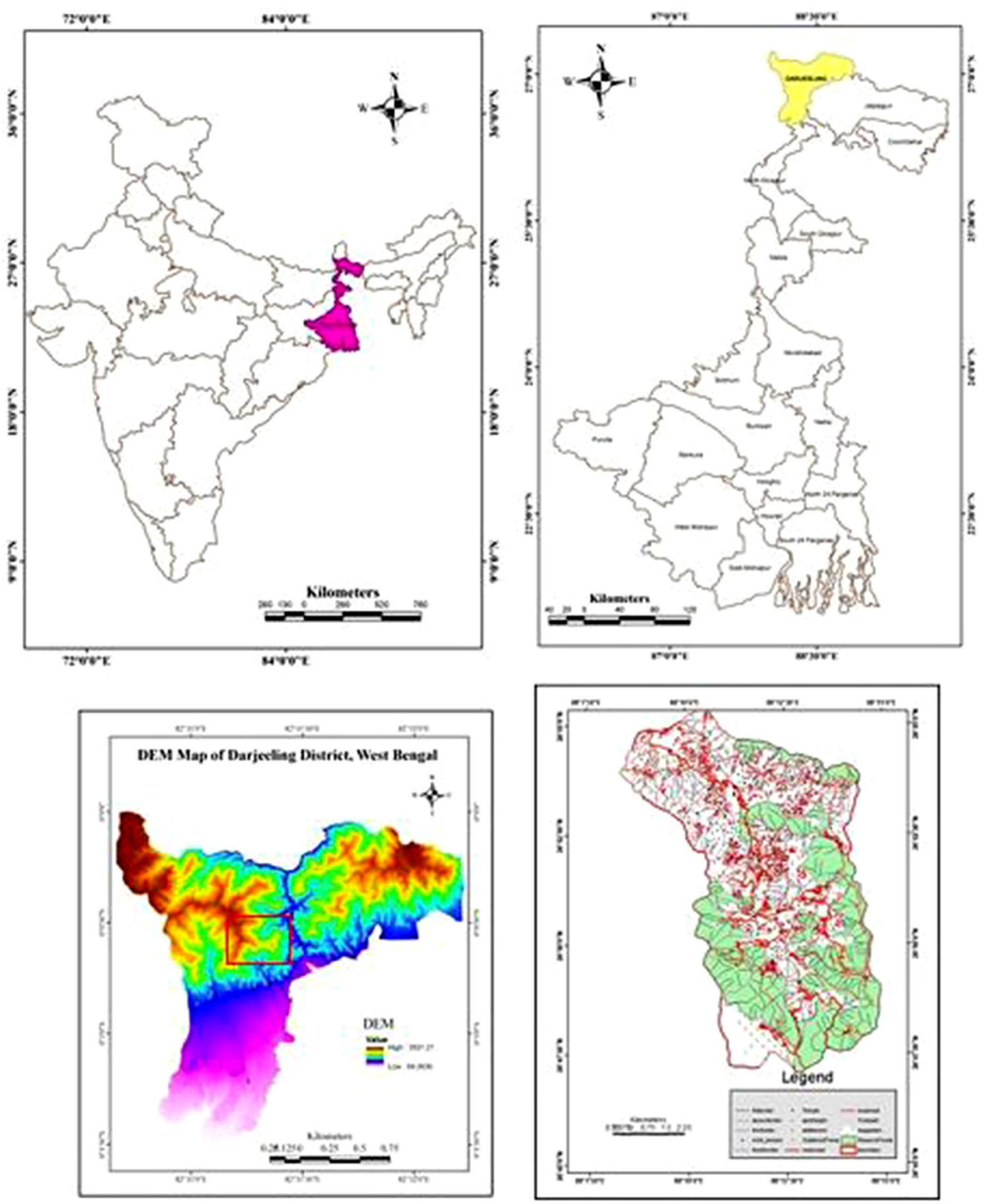

Fig. 1 Location map of Mechi-Balason interfluves

Landslide Susceptibility Index values were derived and then it was overlaid on the actual status of forest map to know the relationship between forest disturbances and landslide occurrences in the Mirik Block of the Darjiling Himalaya.

The forest canopy density model combined three (3) indices i.e. Vegetation Index, Bare Index and Shadow
Index (Fig. 2). Vegetation Index includes all type of vegetations such as the forest and grassland. Advanced Vegetation Index (AVI) reacts sensitively to the vegetation quantity compared with NDVI. Shadow Index (SI) increases as the forest density increases. Bare Soil Index increases as the bare soil exposure degrees of ground increase. These index values were calculated pixel wise. 
Fig. 2 Flow chart of the methodology

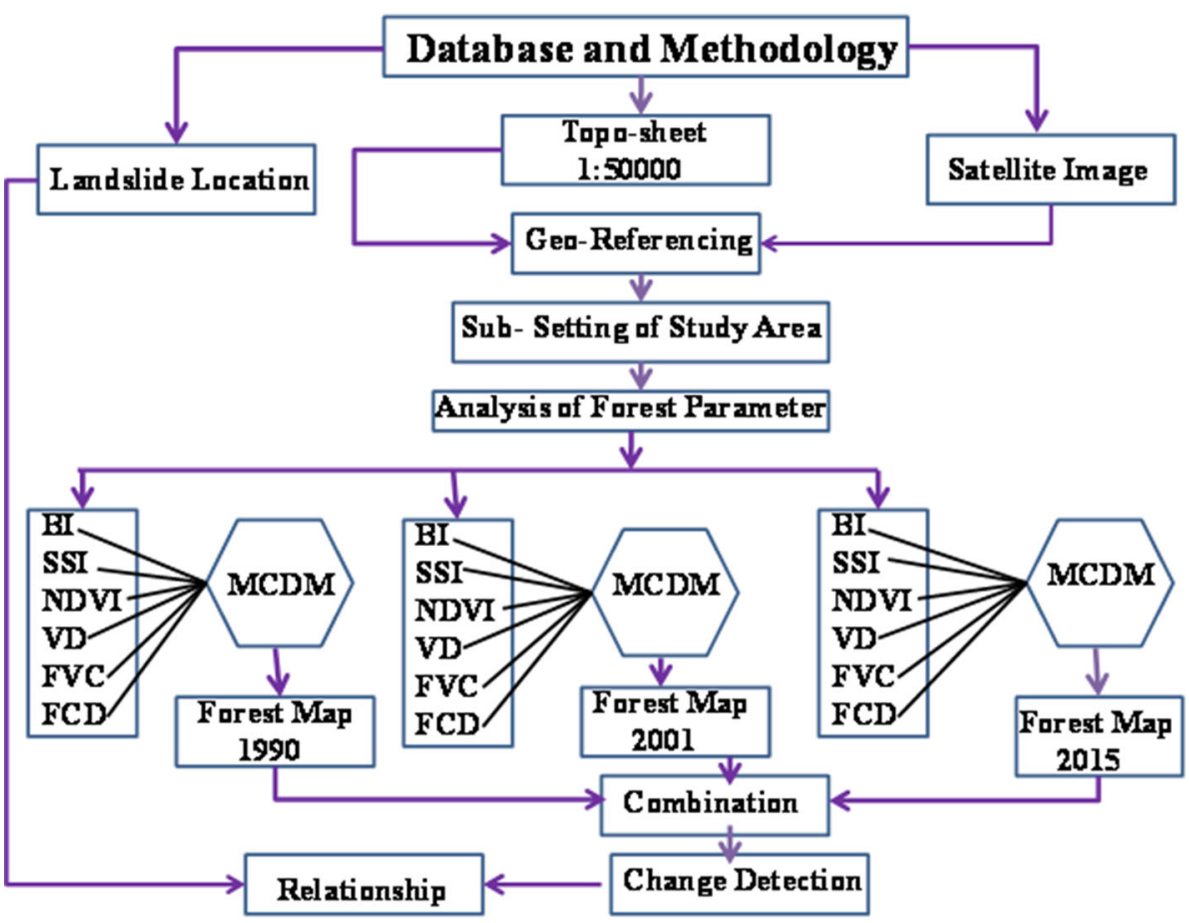

\section{Advanced Vegetation Index (MAVI)}

NDVI is unable to highlight subtle differences in canopy density. It is necessary to improve by using power degree of the infrared response. The calculated index has been termed as Advanced Vegetation Index (AVI). It is sensitive to forest density and physiognomic vegetation classes. AVI was estimated using Eq. 1:

$\mathrm{AVI}=\{(\mathrm{B} 4+1)(256-\mathrm{B} 3)(\mathrm{B} 4-\mathrm{B} 3)] 1 / 3$.

\section{Bare Soil Index (BI)}

The bare soil areas, fallow lands having vegetation cover with marked background responses which are being estimated using this index. Similar to the concept of AVI, the Bare Soil Index (BI) is a normalized index of the difference sums of two separating the vegetation with different background viz. completely bare, sparse canopy and dense canopy etc. BI has been calculated using Eq. 2:

$$
\begin{aligned}
\mathrm{BI}= & (\mathrm{B} 5+\mathrm{B} 3)+(\mathrm{B} 4+\mathrm{B} 1) /(\mathrm{B} 5+\mathrm{B} 3)-(\mathrm{B} 4+\mathrm{B} 1) \\
& \times 100+100 .
\end{aligned}
$$

\section{Shadow Index (SI)}

One unique characteristic of a forest is its three dimensional structure. To extract information on the forest structure from RS data, the new methods which examine the characteristics of shadow by utilizing (a) spectral information on the forest shadow itself and (b) thermal information on the forest influenced by shadow. The Shadow Index is formulated through extraction of the low radiance of visible bands (Eq. 3),

$$
\mathrm{SI}=((256-B 1) \times(256-B 2) \times(256-B 3))^{\wedge} 1 / 3 .
$$

\section{Scaled Shadow Index (SSI)}

The Shadow Index (SI) is a relative value. Its normalized value can be utilized for calculation with other parameters. The SSI was developed in order to integrate MAVI values and SI values. In areas where the SSI value is zero, this corresponds with forests that have the lowest shadow value (i.e. $0 \%$ ). In areas where the SSI value is 100 , this corresponds with forests that have the highest possible shadow value (i.e. $100 \%$ ). SSI was obtained by linear transformation of SI. With the development of SSI one can clearly differentiate between vegetation in the canopy and vegetation on the ground. It significantly improves the capability to provide more accurate results from data analysis than it was possible in the past.

\section{Vegetation density (VD)}

It is the procedure to synthesize VI and BI. By using principal component analysis VD was estimated in the present work. VI and BI have high negative correlation and analyzed after Rikimaru (1996). The higher value of 
vegetation density indicates the higher concentration of vegetation per unit of area on the lover value of vegetation density is an indication of low concentration of vegetation per unit area.

\section{$F C D$}

For the detail analysis of forest disturbance of Mirik Block a forest canopy density model has been established to show the temporal variation of forest canopy coverage of the study area. FCD model has been prepared for three consecutive years of 1990, 2001 and 2015. Integration of VD and SSI means transformation for forest canopy density value. Both parameter has no dimension and has percentage scale unit of density. It is possible to synthesize both indices safely by means of corresponding scale and units of each. After preparing FCD map of the three consecutive years the FCD map has been classified into four classes according to their percentage coverage of forest canopy. Class 1 is indicate $0-25 \%$ canopy coverage, class 2 is indicate $25-50 \%$ canopy coverage, class 3 is indicate $50-75 \%$ canopy coverage and class 4 is indicate $75-100 \%$ canopy coverage. For the detail analysis of nature of forest disturbances in terms of forest canopy density, all the forest canopy classes raster map has been merged to each other and converted them into vector to find out the pixels which has been converted into another pixel to find out the degenerated, regenerated and unchanged pixel of the map. Hence the three years map has been merged to each other,

$\mathrm{FCD}=(\mathrm{VD} \times \mathrm{SSI}+1) 1 / 2-1$.

\section{NDVI}

The Normalized Difference Vegetation Index (NDVI) is a numerical indicator that uses the visible and near-infrared bands of the electromagnetic spectrum, and is adopted to analyze remote sensing measurements and assess whether the target being observed contains live green vegetation or not. The NDVI algorithm subtracts the red reflectance values from the near-infrared and divides it by the sum of near-infrared and red bands,

$\mathrm{NDVI}=(\mathrm{NIR}-\mathrm{RED}) /(\mathrm{NIR}+\mathrm{RED})$.

This formulation allows us to cope with the fact that two identical patches of vegetation could have different values if one were, for example in bright sunshine, and another under a cloudy sky. The bright pixels would all have larger values, and therefore a larger absolute difference between the bands. This is avoided by dividing by the sum of the reflectances.

\section{Fractional vegetation cover}

Fractional vegetation cover (FVC) is an important surface property, namely because it determines the size of the vegetated portion of the land surface that will be communicating with the atmosphere. This vegetated fraction can transpire, evaporate, absorb radiation, and store energy depending on the area of leaves per area of ground, a property known as Leaf Area Index (LAI). It is the outcome of the contribution of NDVI from vegetated and nonvegetated surfaces (Eq. 6),

FVC = NDVImax - NDVIs / NDVIv - NDVIs,

where the subscript max indicates the maximum NDVI observed during the 12 months period; the subscript $v$ indicates the NDVI value that corresponds to $100 \%$ vegetation cover for each of the seventeen International Geosphere-Biosphere Program (IGBP) land cover types, and the subscript $s$ indicates the NDVI value for bare soil.

\section{Landslide Susceptibility Index (LSI)}

To find out the causes of FCD disturbance in the study area a relationship has been drawn between landslide occurrence and FCD. For this study a landslide inventory map was prepared identifying landslide locations by intensive field investigation with GPS and in consultation with Google Image, Survey of India (SOI) Topo-sheet (1972) and Satellite Images (2015) and then Landslide Susceptibility Index value has been calculated for each unchanged, regenerated and degenerated FCD area using Landslide Susceptibility Index model (Eq. 7). To obtain Landslide Susceptibility Index $\%$ of landslide $/ \mathrm{km}^{2}$ and vegetation density was estimated on GIS platform (Eq. 7). To perform LSI model, landslide susceptibility value was assigned following 10 point scale. Very high vegetation density locations were assigned with the value close to 0 and vice versa,

Landslide Susceptibility Index (LSI)

$$
=\% \text { of landslide per } \mathrm{km}^{2} / 100 \times \mathrm{LSV} \text {. }
$$

\section{Result and discussion}

\section{Soil Bareness Index, Shadow Index, and Scaled Shadow Index}

In Mirik Block of Darjiling Himalaya the steep flank slope on both side of the divide summit Soil Bareness Index is high where landform is exposed to atmospheric process and experienced with surface run-off and soil erosion (Fig. 3). 
Fig. 3 Soil Bareness Index

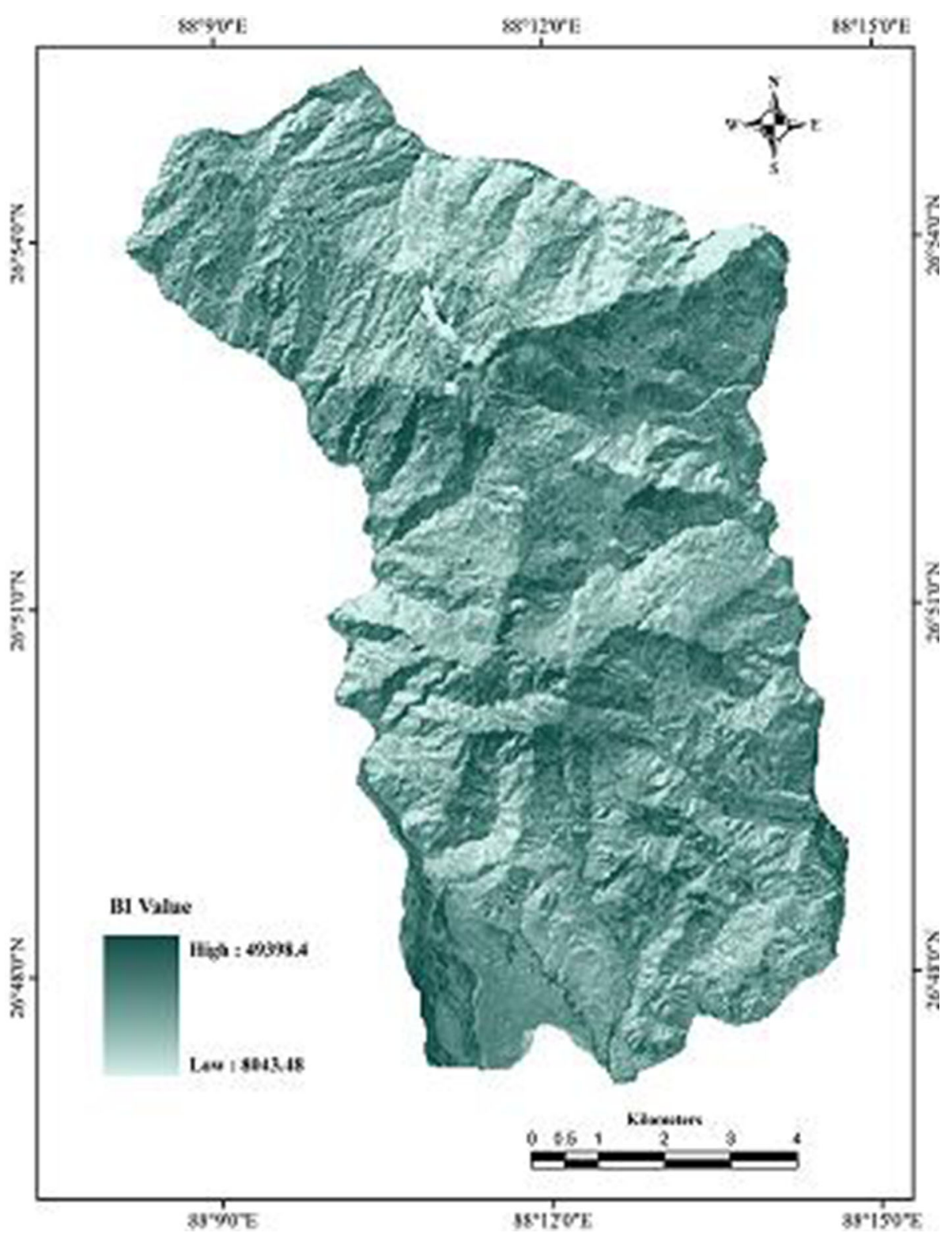

Basically lower most segments is characterized by low value of Bareness Index and less exposed the atmospheric processes. In the study area SI value ranges from 143.39 to 228.78. The extreme northern part is characterized by high Shadow Index and where the vegetation density is also high. This situation leads to the saturation of the slope materials throughout the year and may reduce the soil cohesion. Middle most section of the mountain slope in Mirik Block is registered with low Shadow Index and less vegetation cover (Fig. 4). Scale Shadow Index is the modified form of Shadow Index. It was also found that the northern part and western flank of the mountain slope were dominated high scale Shadow Index value where vegetation density as well and canopy density were at high level (Fig. 5).

\section{Vegetation Index, NDVI and Fractional Vegetation Index}

Vegetation density varies from one place to another in Mirik Block. High vegetation density was observed in the northern part of the study area, middle most section was dominated moderate to low vegetation density (Fig. 6). NDVI is an indication of slope vegetation and soil moisture situation over the space. In Mirik Block of Darjilng Himalaya, gentle slope is dominated by low NDVI value where soil moisture condition is also high. On the other hand steep slope were being characterized by high NDVI values and sparse vegetation cover (Fig. 7). Fractional Vegetation Index or Leaf Area Index is high in the north eastern and middle most section of the study area where 
Fig. 4 Shadow Index

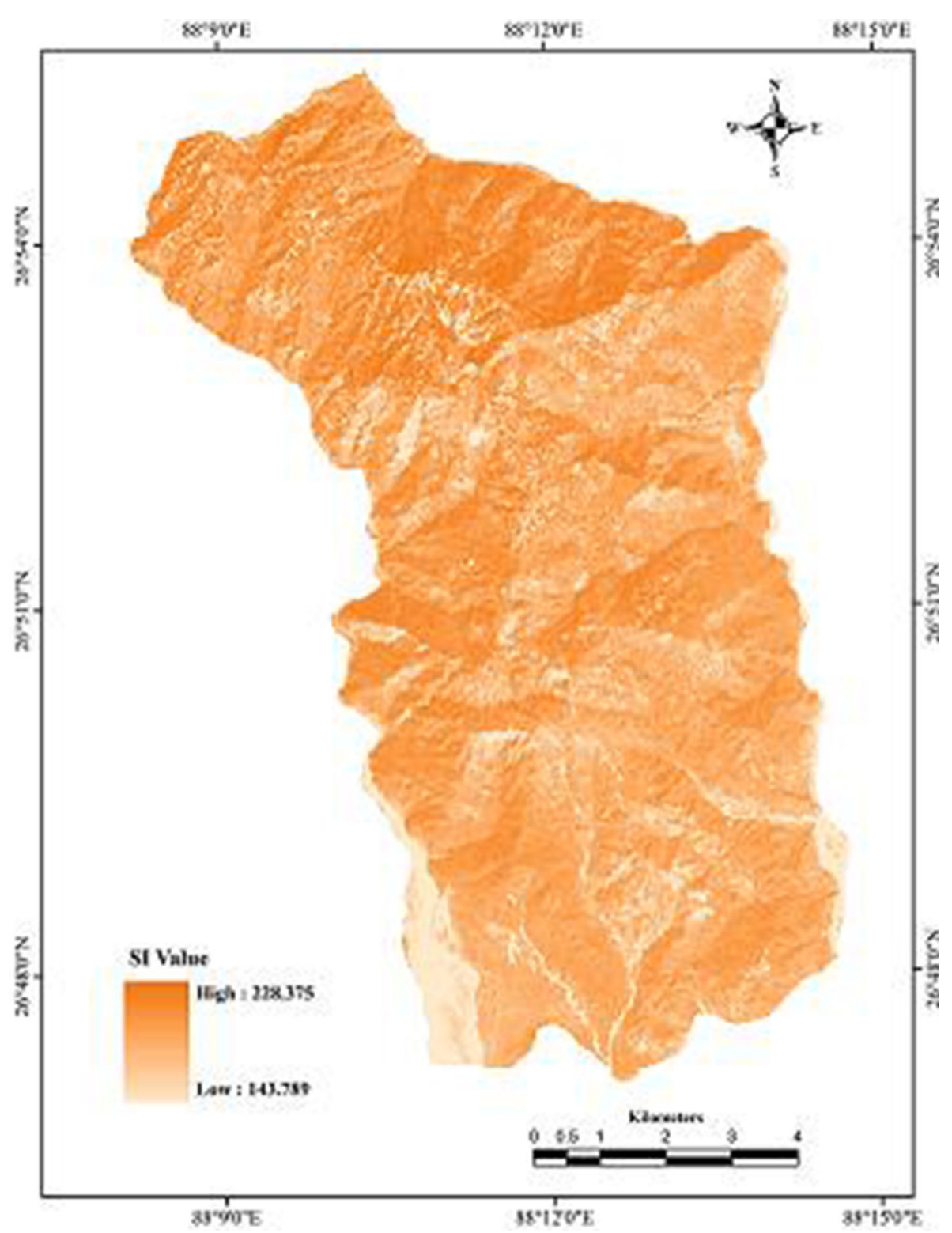

slope soil largely controlled as a result of controlled solar radiation, transpiration and evaporation by vegetation cover (Figs. 8, 9).

\section{Forest canopy density analysis}

From the analysis of the FCD map of 1990 and 2015 it has been found that $29.98 \mathrm{~km}^{2}$ areas were unchanged, $24.43 \mathrm{~km}^{2}$ areas were regenerated and $39.13 \mathrm{~km}^{2}$ areas were degenerated out of total area of $96.67 \mathrm{~km}^{2}$ of the study area. The pattern of FCD map also shows the greater area were degenerated than the regenerated and unchanged forest pattern which is an indication of the direct loss of forest canopy in the form of forest loss. On the other hand, FCD map of 2001 and 2015 revealed that $30.2 \mathrm{~km}^{2}$ areas were under unchanged, $36.71 \mathrm{~km}^{2}$ areas were under regenerated and $29.24 \mathrm{~km}^{2}$ areas were under the degenerated condition out of the total area of the study. It was also found that the large area under degenerated of forest canopy were being found from 1990 to 2015 and minimum area were under degenerated conditions (Fig. 10). From this uneven status of degeneration of forest canopy it can be concluded that before 2000 there was an extreme vegetation degradation which was caused as a result of human intervention i.e. illegal felling of trees, expansion of human settlement, and modification of hill slope for the establishment of tea garden area. On the other hand after 2001, Govt. took an initiatives for improving vegetation cover and reducing land degradation by introducing plantation and afforestation programme and as a result of which degenerated canopy coverage has been slightly decreased than the previous year (Fig. 11). 
Fig. 5 Scaled Shadow Index

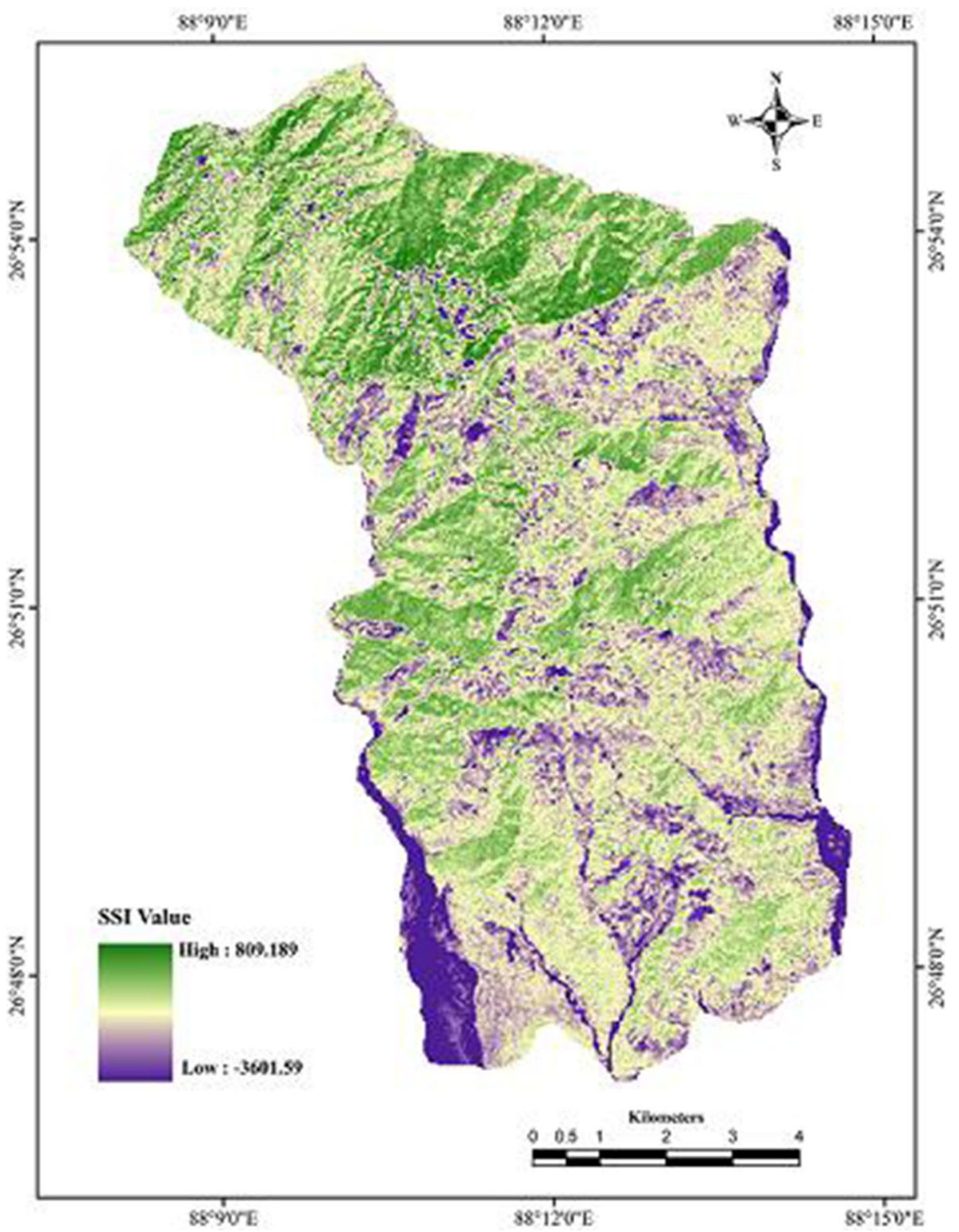

\section{Relationship between forest canopy density and landslide occurrences}

Disturbance in FCD may be caused by different factors like; Increasing rate anthropogenic activity in forested area, different kind of natural hazard like; landslide, rainfall, topography, etc. occurring in the hilly area. On the other hand the occurrences of landslide in the study area in increasing in day by day. To find out the causes of FCD disturbance in the study area a relationship has been drawn between landslide occurrence and FCD. For this study a landslide inventory map has been prepared and Landslide Susceptibility Index value has been calculated for each unchanged, regenerated and degenerated FCD area. The study reveals that the landslide susceptibility values are very high in degenerated forest canopy coverage than both the regenerated and unchanged forest canopy cover. The change in 2001-2015 and 1990-2015 both the year represents more or less same situation (Tables 1, 2). The relationship between landslide occurrence and status of forest canopy coverage is strongly positive and hence it can be concluded that apart from the other factor which causes disturbance in forest canopy coverage landslide is also one of the causative factors for landslide. The high landslide susceptibility value indicates the more chance of landslide occurrence and the higher occurrences of landslide will leads to the destruction of forest cover which will affect the forest canopy coverage of the study area. 
Fig. 6 Vegetation Density

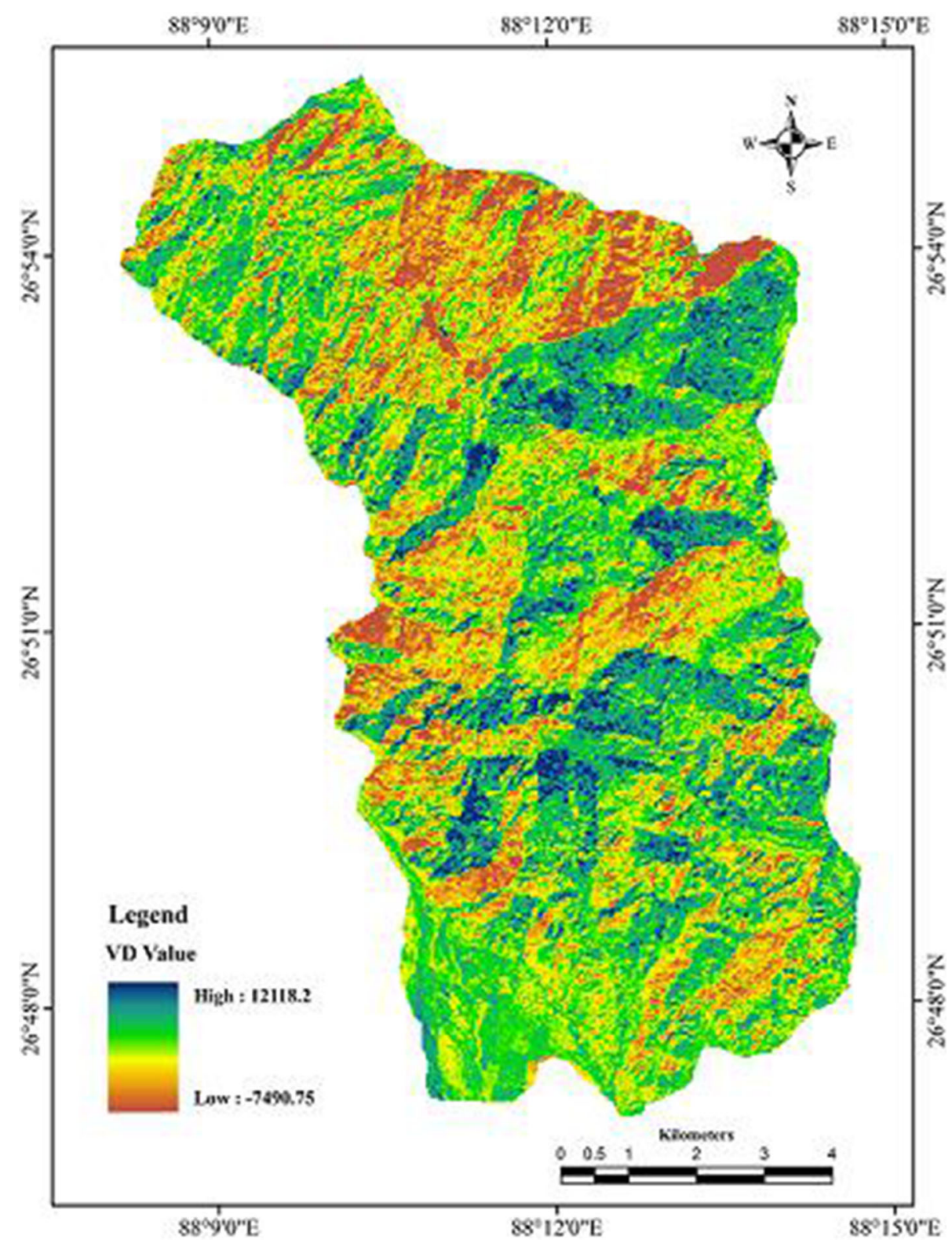

\section{Forest pattern for the year 1990, 2001 and 2015}

To get the forest map of the Mirik Block all the six physiognomic parameter of forest which has been prepared by following Forest Survey of India (2000) band algebra has been combined by using Multi Criteria Decision Making (MCDM) Approach on the basis of Satty's Rank Sum Method (Table 3),

$\frac{X-R j+1}{\sum X-R k+1}=W i J$

where, $X=$ criteria; $R j=$ rank; $R k=$ serial number of the parameter; and $\mathrm{Wij}=$ assigned weight.

After assigning the weight a linear regression has been formed to create the forest map and this way the forest map of this three consecutive years has been prepared. Now to classify the forest in several classes like extremely high, extremely-high, high-open, open-shrubs etc. all the forest raster has been standardize using $\mathrm{Z}$ score and in this way the forest class has been prepared. The forest map of different years shows that there is spatial and temporal change has been found in the map. The analysis also shows that from 1990 to 2001 the areal coverage of forest has been increased (Fig. 12). On the other hand in 2015 the areal coverage of forest has been decreased than the previous year. Contrary to this the amount of bare surface or nonvegetative area has been increased than 2001 in 2015 . The causes behind the increase of forest area in 2001 than 1990 it can be said that the different social forestry programme, afforestation programme has been taken at that time are the major responsible factors. 
Fig. 7 NDVI

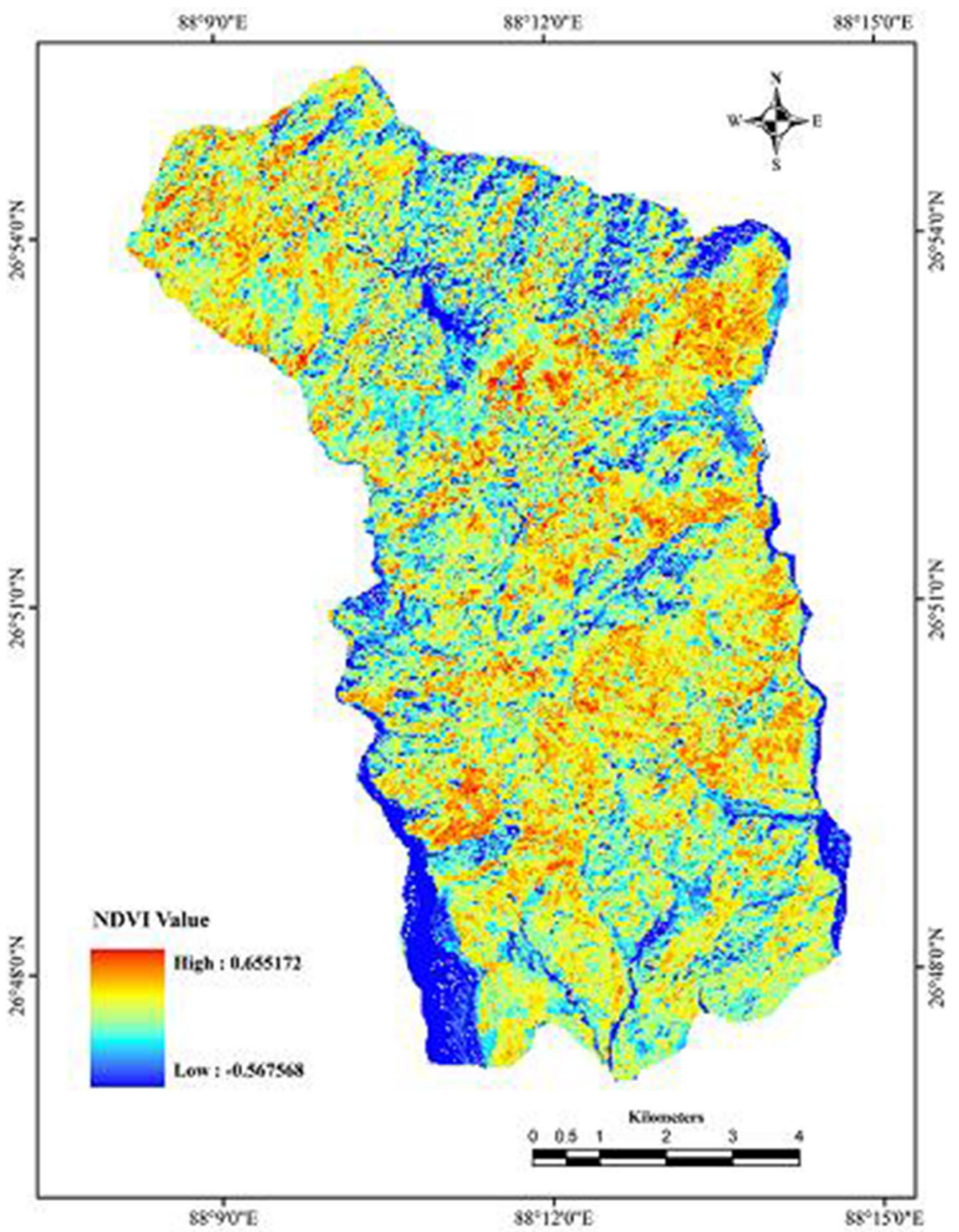

\section{Changing pattern of forest cover in Mirik Block}

To know the change of forest pattern of Mirik Block the reclassified forest cluster map was combined to get the actual regeneration, degeneration and unchanged condition of forest cluster and the actual changing pattern of forest map in terms of regeneration, degeneration and unchanged forest map of three consecutive years i.e. 1990, 2001 and 2015 was prepared. From both the forest pattern change map and the areal forest pattern change it was found that a large section of the forest area was degenerated in 1990 than 2001. The analysis also dealt that a large amount of forest has been cleared during this period. But after 2000 the state government took the initiative in the form of social forestry programme and joint forest management programme to reduce the loss of forest coverage. As a result, the degeneration rate has been decreased during that period. On the other hand, the overall change in the forest cover from 1990 to 2015 showed that the rates of forest disturbance were increased day by day (Fig. 13). So it can be said that the role of natural hazard plays an important role for the forest disturbance in this area.

There was a continuous change in the area of forest pattern in Mirik Block of Darjiling Himalaya. Since 1990-2001, around 40\% area was degenerated and $13 \%$ area was unchanged. During the time period between 2001 and 2015 degenerated area (around 36\%) was increased and regenerated area decreased (32\%) (Fig. 14). But as a result of various programme the regenerated forest area has been increased since 1990-2015 (Fig. 14c). 
Fig. 8 Fractional vegetation cover

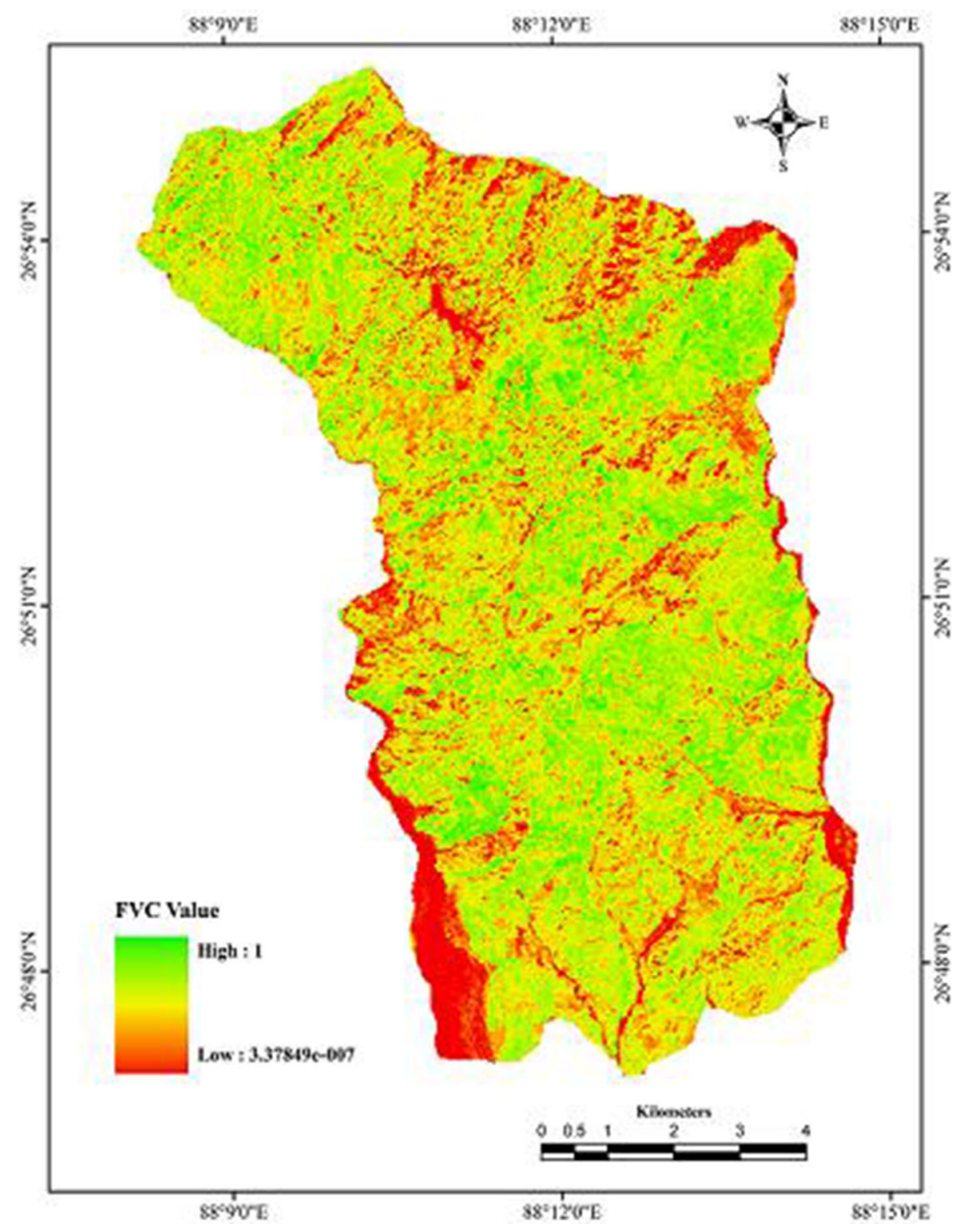

\section{Relationship between Landslide Susceptibility Index and potentiality of forest disturbance}

From the overall study it can be found that the number of landslide occurrences (Fig. 15) and the Landslide Susceptibility Index value both are higher in the degenerated of part of the FCD in all the years. It could be assumed that degeneration of the slope leads to the exposure of the landform to atmospheric processes which leads to slope instability. The studies revealed that during the period 2001-2015 Landslide Susceptibility Index of degenerated, regenerated and unchanged forest area are 6.24, 2.29 and 1.47 (Table 4). Since 1990-2015, forest degeneration was also noticeable and it covered the area of $42.14 \%$ in the study area where Landslide Susceptibility Index was 6.24. The unchanged area is attributed with low landslide susceptibility during 2001-2015 and 1990-2015 which depicted that human intervention and modification of slope are the most important contributing factors for degeneration and landslides in Mechi-Balason interfluves of Darjiling Himalaya (Table 5). It was observed from the study that most of the landslide locations are located in the degenerated forest pattern and where the landslide potentiality was also at high level (Fig. 16). The degenerated areas provide a suitable geomorphic and geohydrologic situation over the mountain slope in Mechi-Balason interfluves areas of Darjiling Himalaya and invite landslides frequently. 

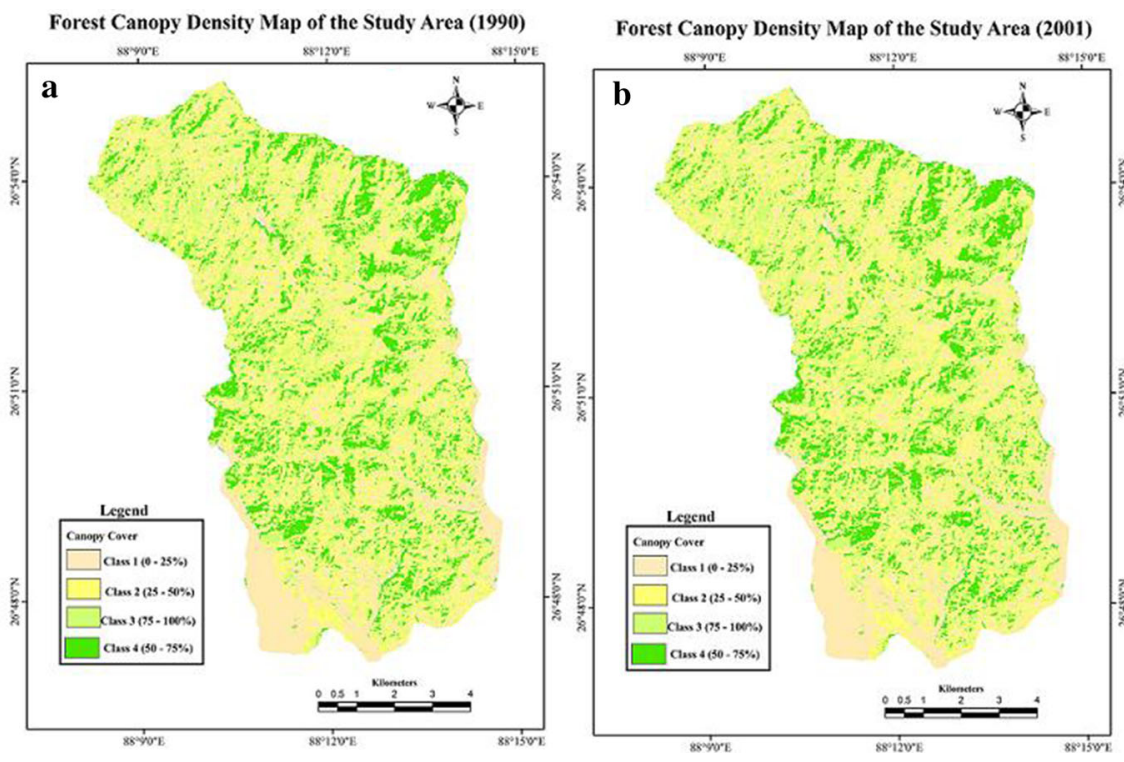

Forest Canopy Density Map of the Study Area (2015)

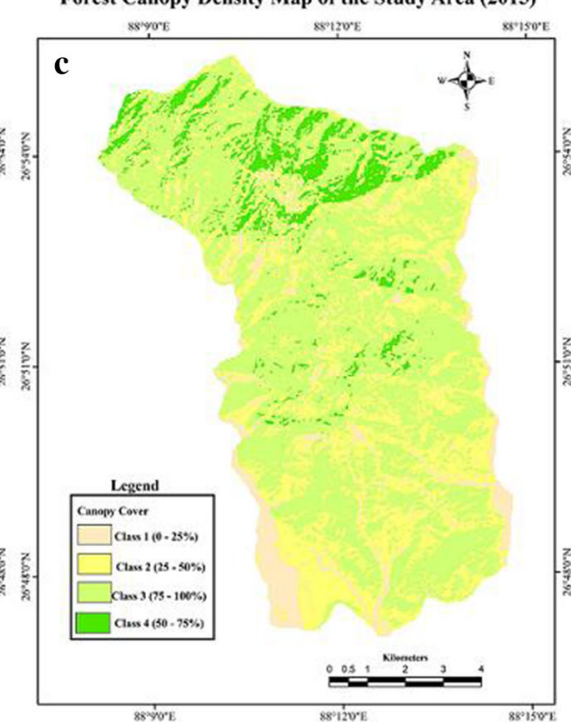

Fig. 9 Forest canopy density map for the year 1990 (a), 2001 (b) and 2015 (c)

Change in Forest Canopy Density in Mirik Block (1990-2015)

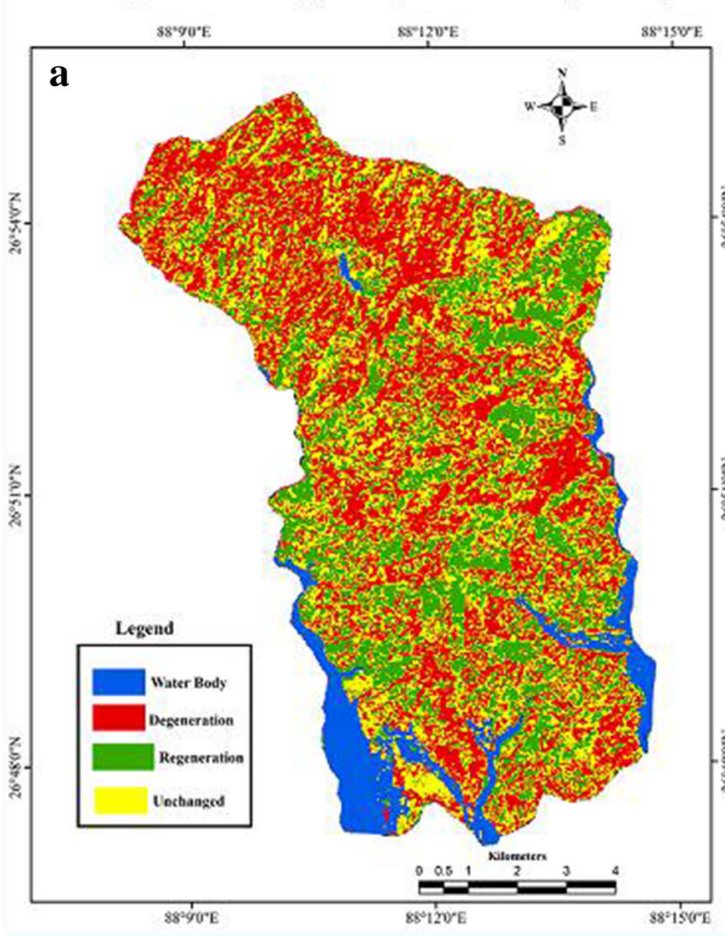

Changing Pattern of Forest Canopy Density in Mirik Block (2001-2015)

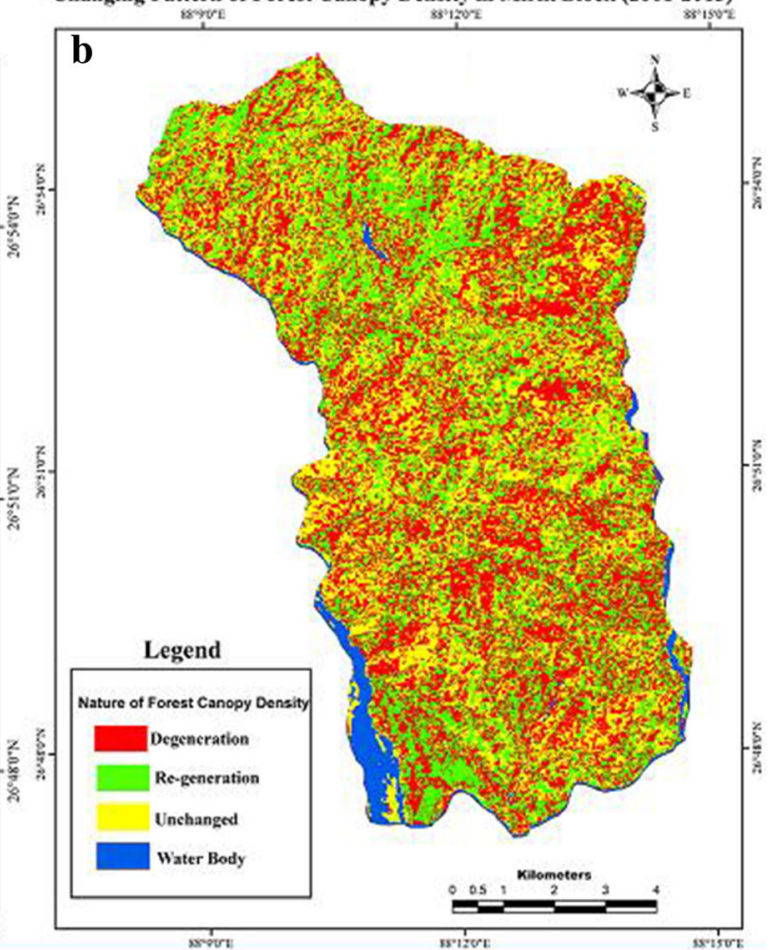

Fig. 10 Change of Forest Canopy Density during 1990-2015 (a) and 2001-2015 (b)

\section{Conclusion}

Hydrologic condition indicates the effects of cover type and treatment on infiltration and runoff and is generally estimated from density of plant and residue cover on sample areas or refers to the state of vegetation growth. A poor hydrologic condition refers to pasture heavily grazed with sparse vegetation. A fair condition is for pasture moderately grazed with between half and 3/4th of the basin under plant cover i.e. the basin has 50-25\% plant cover. A good hydrologic condition indicates that the soil usually has a low runoff potential for the given hydrologic soil group, land cover type and treatment. Some factors are consider in estimating the effects of cover on infiltration and runoff are (1) Canopy or 

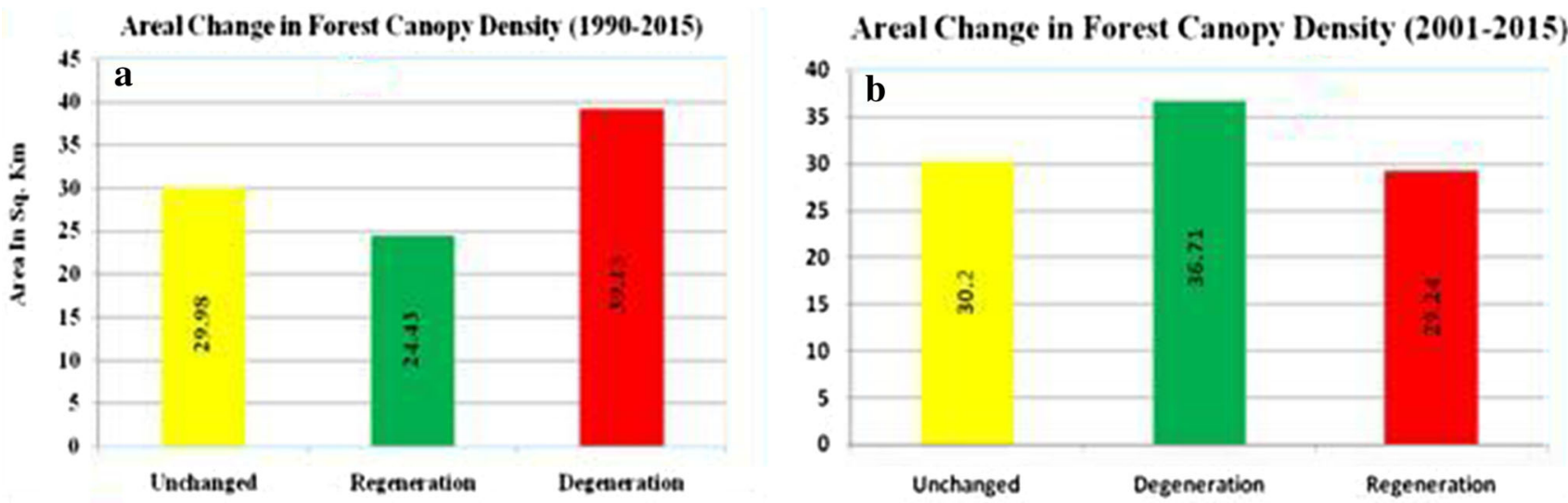

Fig. 11 Areal change of Forest Canopy Density during 1990-2015 (a) and 2001-2015 (b)

Table 1 Landslide Susceptibility Index for forest canopy density map during 2001-2015

\begin{tabular}{lllllll}
\hline Sl no. & $\begin{array}{l}\text { Forest } \\
\text { pattern/type }\end{array}$ & Area in $\mathrm{km}^{2}$ & No. of landslide & $\begin{array}{l}\text { Landslide per } \\
\mathrm{km}^{2}\end{array}$ & \% of landslide per $\mathrm{km}^{2}$ & $\begin{array}{l}\text { Landslide Susceptibility Index } \\
\text { (LSI) }\end{array}$ \\
\hline 1 & Degenerated & 36.71 & 102 & 2.78 & 60.04 & 6.00 \\
2 & Regenerated & 29.24 & 32 & 1.09 & 23.54 & 2.35 \\
3 & Unchanged & 30.20 & 23 & 0.76 & 16.41 & 1.64 \\
\hline
\end{tabular}

Table 2 Landslide Susceptibility Index for forest canopy density map during 1990-2015

\begin{tabular}{lllllll}
\hline Sl. no. & Forest pattern & Area in $\mathrm{km}^{2}$ & No. of landslide & Landslide per $\mathrm{km}^{2}$ & $\%$ of landslide per $\mathrm{km}^{2}$ & Landslide Susceptibility Index (LSI) \\
\hline 1 & Degenerated & 39.13 & 88 & 2.25 & 46.29 & 4.63 \\
2 & Regenerated & 24.43 & 41 & 1.68 & 35.89 & 3.59 \\
3 & Unchanged & 29.98 & 28 & 0.93 & 19.87 & 1.99 \\
\hline
\end{tabular}

Table 3 Calculation of weighted index by using Satty's Rank Sum Method

\begin{tabular}{llllll}
\hline S1. no. () & Parameter & Rank () & $\mathrm{x}-+1$ & $\mathrm{x}-+1$ & \\
\hline 1 & FCD & 1 & 6 & 6 & 0.2857 \\
2 & NDVI & 4 & 5 & 3 & 0.1428 \\
3 & FVC & 3 & 4 & 4 & 0.1904 \\
4 & VD & 2 & 3 & 5 & 0.23809 \\
5 & BI & 6 & 2 & 1 & 0.4761 \\
6 & SSI & 5 & 1 & 2 & 0.09523 \\
\hline
\end{tabular}

density of lawns, crops or other vegetation areas; (2) amount of year-round cover; (3) amount of grass or close seeded legumes in rotations; (4) percent of residue cover; and (5) degree of surface roughness. The earth surface is attributed with different kind of vegetation cover which varies from one slope segment to another one. Such variation leads to the variation in hydrologic behaviour of the slope soil (Table 6). The high vegetation density, forest canopy density, regenerated forest area in the Mechi-Balason interfluves area introduce very god hydrologic condition with low run-off potential and less soil erosion and slope failure phenomena. This kind of land surface is being found in the north eastern, western, and some lower most slope in the study area. The middle most section of the slope is attributed with less vegetation cover, degeneration of the forest, and low canopy density where run-off potentiality and soil erosion as well as slope failure also high. All these places should be brought under plantation and afforestation programme to increase the areal extent of forest canopy density, vegetation density and regenerated area to mitigate soil erosion and slope instability in Mirik Block of Darjiling Himalaya.

Jute Geotextiles are the most effective among all types of geotextiles-both natural and man-made which can improve the degenerated areas in Mirik Block. Additionally, hygroscopic nature of jute yarns in the Jute Geotextile cause them to swell by around $20 \%$ when wet. This situation will promote to reduce the velocity of sub-surface water as well as entrapment of soil particles. Before netting the slope, a fertilizer is to be spread on the slope in order to promote faster 

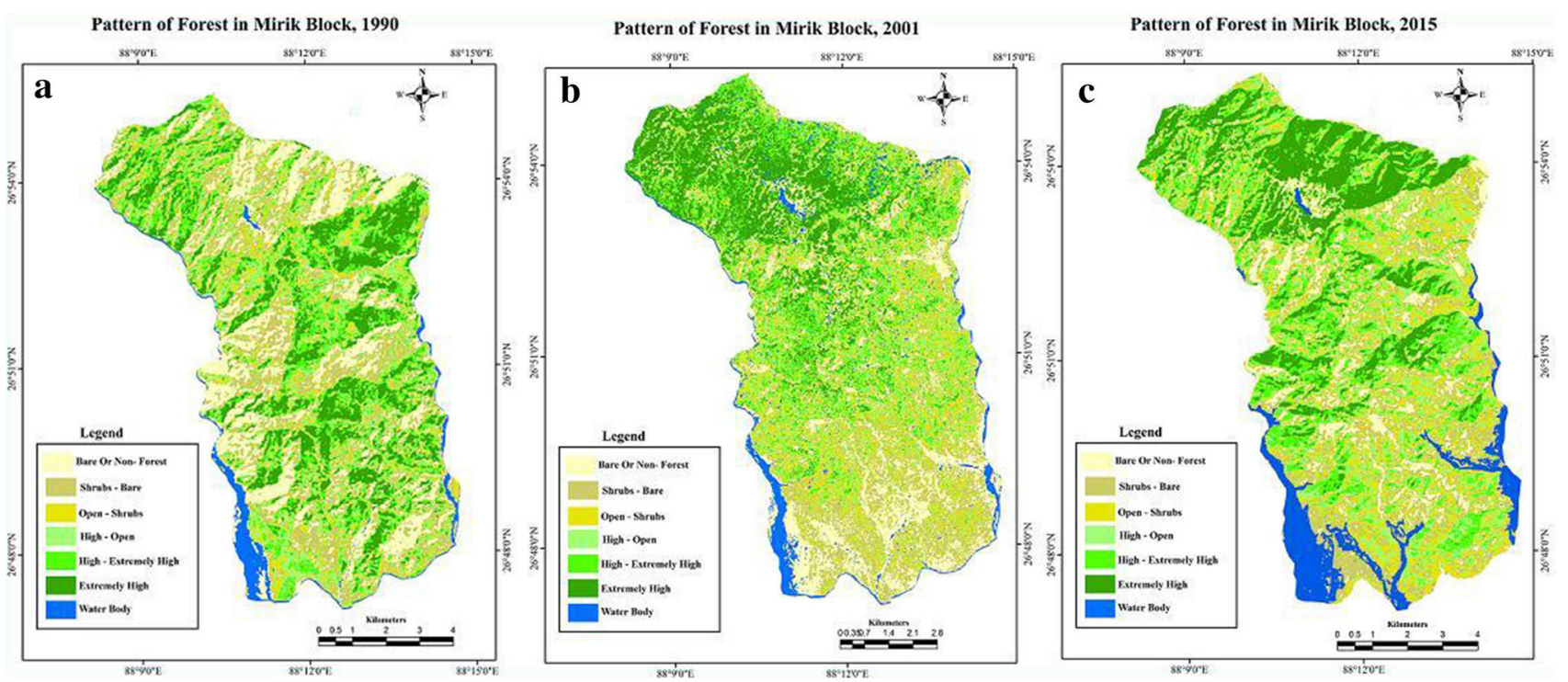

Fig. 12 Pattern of forest cover for the year 1990 (a), 2001(b) and 2015 (c)
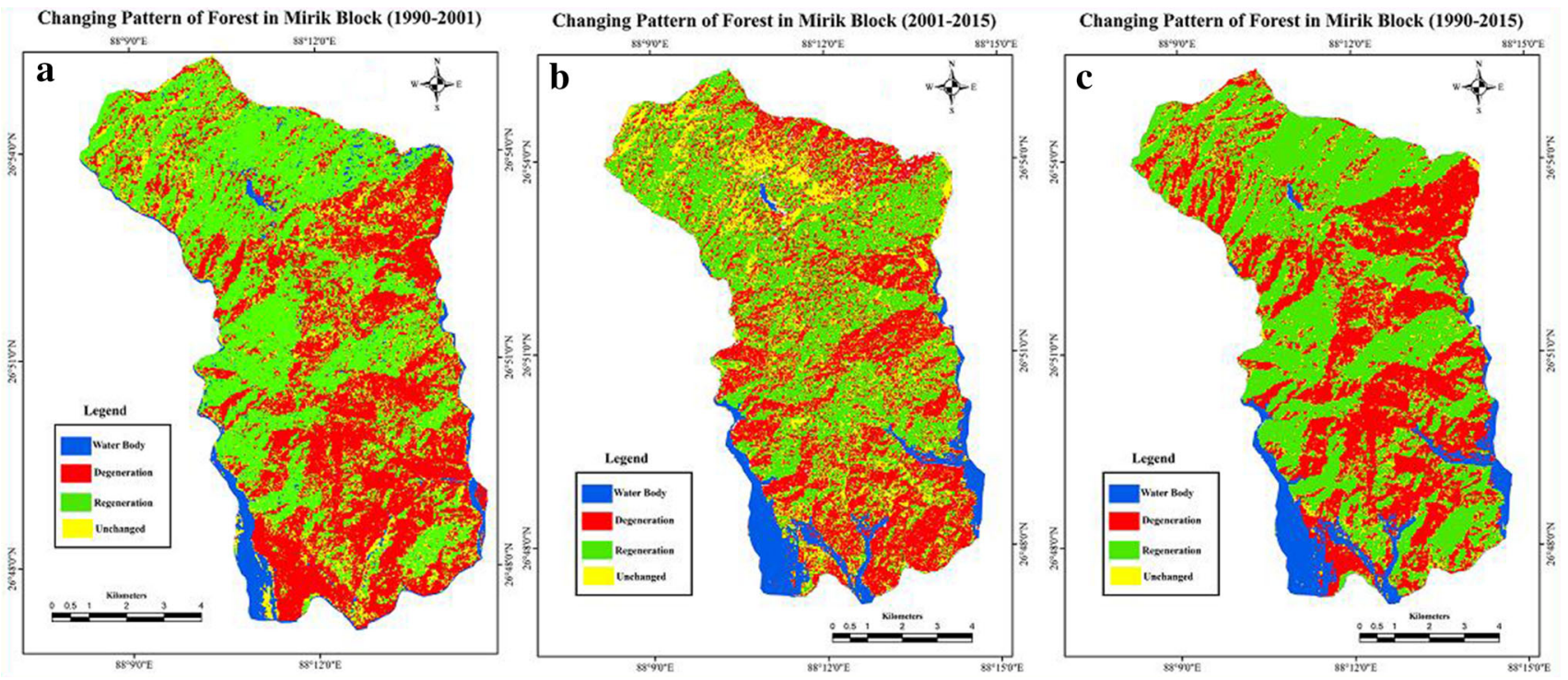

Fig. 13 Changing Pattern of forest cover in Mirik Block during 1990-2001 (a), 2001-2015 (b) and 1990-2015 (c)
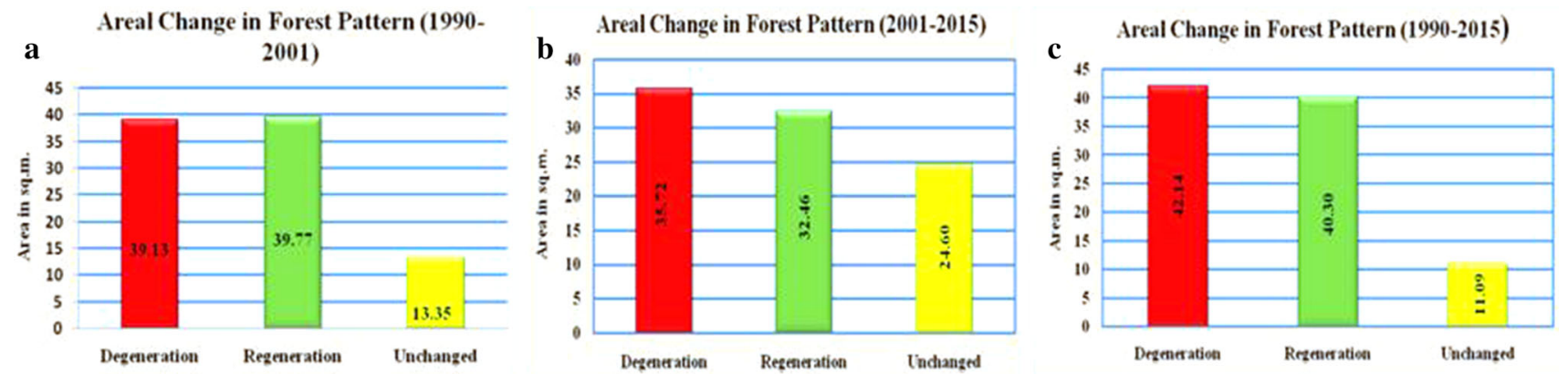

Fig. 14 Areal change in the forest pattern during 1990-2001 (a), 2001-2015 (b) and 1990-2015 (c) 
Fig. 15 Landslide locations map of Mirik Block

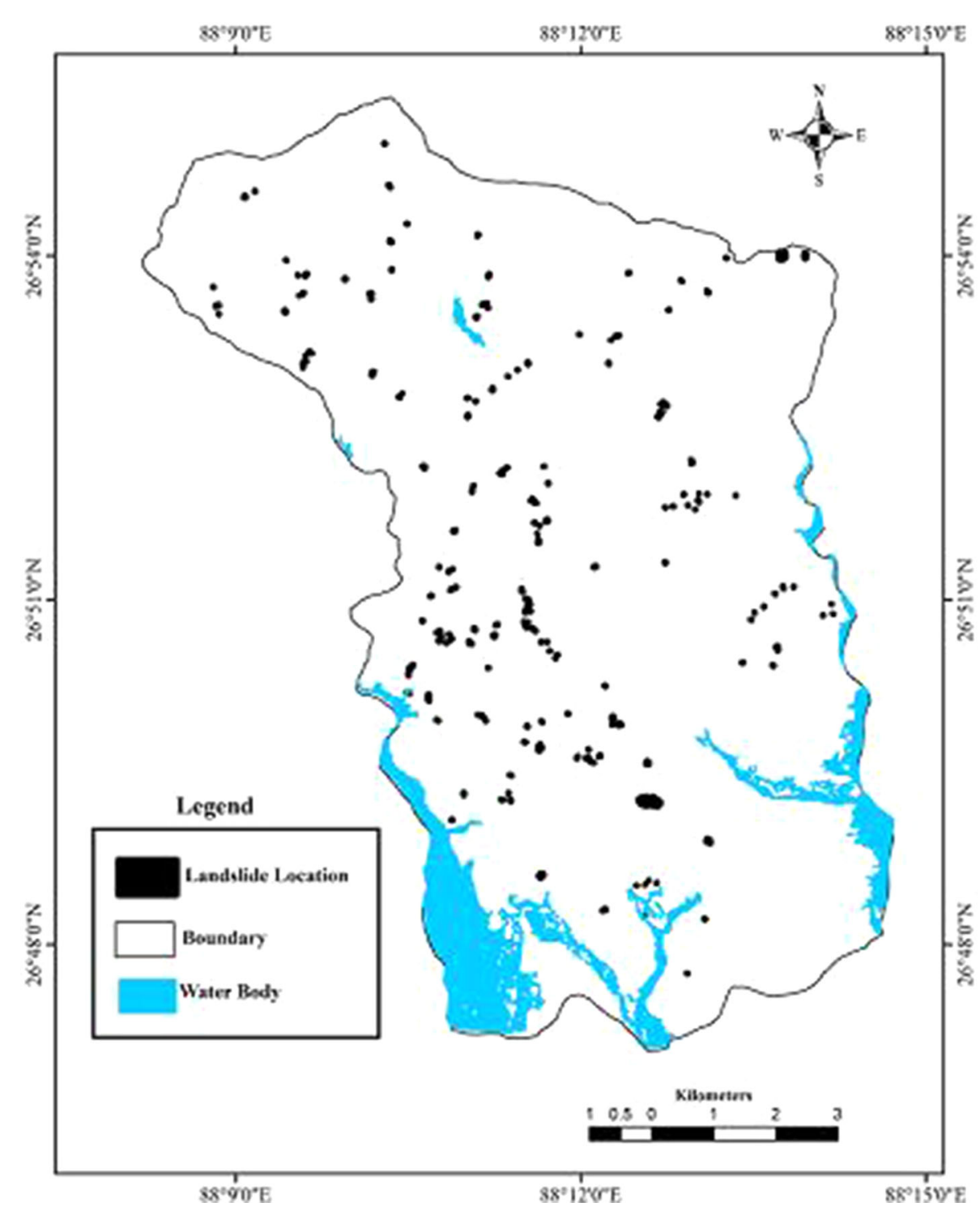

Table 4 Landslide Susceptibility Index for forest map of the year 2001-2015

\begin{tabular}{lllllll}
\hline Sl. no. & Forest pattern & Area in $\mathrm{km}^{2}$ & No. of landslide & Landslide per km & \% of landslide per $\mathrm{km}^{2}$ & Landslide Susceptibility Index (LSI) \\
\hline 1 & Degenerated & 39.13 & 98 & 2.50 & 62.42 & 6.24 \\
2 & Regenerated & 39.70 & 36 & 0.91 & 22.93 & 2.29 \\
3 & Unchanged & 13.35 & 23 & 1.72 & 14.65 & 1.47 \\
\hline
\end{tabular}

Table 5 Landslide Susceptibility Index for forest map of the year 1990-2015

\begin{tabular}{lllllll}
\hline Sl. no. & Forest pattern & Area in $\mathrm{km}^{2}$ & No. of landslide & Landslide per $\mathrm{km}^{2}$ & \% of landslide per $\mathrm{km}^{2}$ & Landslide Susceptibility Index (LSI) \\
\hline 1 & Degenerated & 42.14 & 99 & 2.35 & 63.05 & 6.31 \\
2 & Regenerated & 40.30 & 35 & 0.87 & 22.29 & 2.22 \\
3 & Unchanged & 11.09 & 23 & 2.07 & 14.65 & 1.46 \\
\hline
\end{tabular}



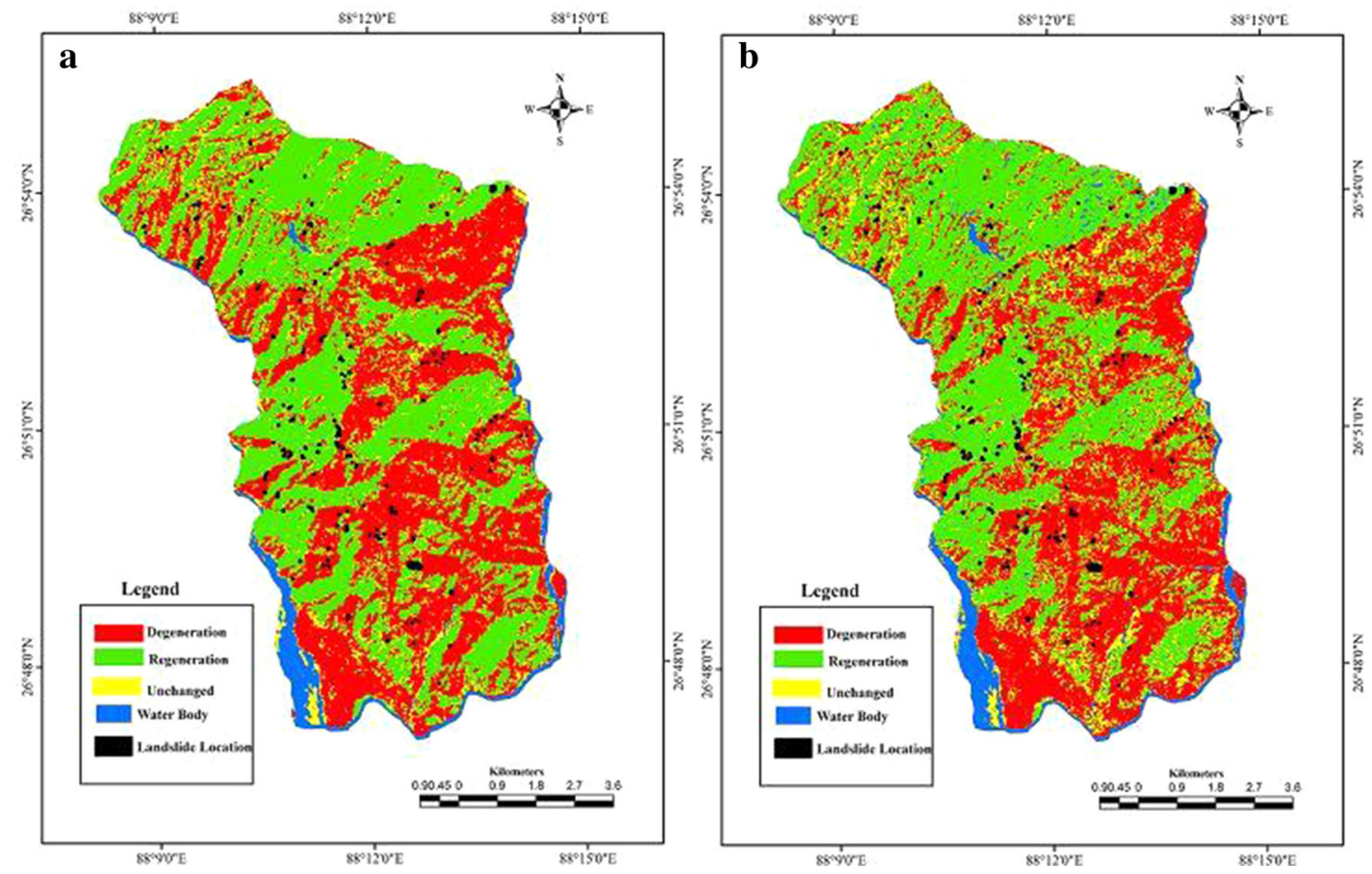

Fig. 16 Locations of landslides in different forest pattern during 1990-2015 (a) and 2001-2015 (b)

Table 6 Land use/land cover and their hydrologic conditions

\begin{tabular}{|c|c|c|}
\hline Vegetation cover and land use type & Intensity and characters & Hydrologic conditions \\
\hline \multicolumn{3}{|l|}{ Bared surface } \\
\hline Steep slope & Without any residue cover & Poor \\
\hline Gentle slope & Without any residue cover & Poor \\
\hline Agricultural land & Contoured and terrace & Poor \\
\hline \multicolumn{3}{|l|}{ Jungle } \\
\hline Upslope & $50-70 \%$ ground is covered by plant & Fair \\
\hline Down slope & $<50 \%$ ground is covered by plant & Poor \\
\hline \multicolumn{3}{|l|}{ Roads } \\
\hline Concrete & Average $65 \%$ area impervious area & Poor \\
\hline Metal & Average $25 \%$ area is impervious & Fair \\
\hline \multicolumn{3}{|l|}{ Settlement } \\
\hline Compact & $65 \%$ average impervious area & Poor \\
\hline Disperse & $25 \%$ average impervious area & Fair \\
\hline \multicolumn{3}{|l|}{ Tea garden } \\
\hline Upslope & More than $75 \%$ area is covered by tea plantation & Poor \\
\hline Down slope & More than $75 \%$ area is covered by tea plantation & Good \\
\hline \multicolumn{3}{|l|}{ Open forest } \\
\hline Upslope & Grazed but not burned & Fair \\
\hline Down slope & Grazed but not burned & Fair \\
\hline \multicolumn{3}{|l|}{ Degraded forest } \\
\hline Upslope & Forest and tree crops heavily grazed or burned & Poor \\
\hline Down slope & Forest and tree crops heavily grazed or burned & Poor \\
\hline \multicolumn{3}{|l|}{ Mixed forest } \\
\hline Upslope & Wood and grass combination 50 and $50 \%$ & Fair \\
\hline Down slope & Wood and grass combination 50 and $50 \%$ & Good \\
\hline Dense forest & $>90 \%$ ground is covered by plant & Good \\
\hline
\end{tabular}


growth of vegetation and soil on the surface of slope is first graded to remove the unevenness present, where possible. The area may be seeded with very limited quantity of Pennisetum species/Vetiveria species grasses known for quick and easy growth and have root depth nearly equaling the existing soil cover, i.e. around $40-50 \mathrm{~cm}$. The netting of slopes generally will stop the downward movement of slope materials as it reduces the impact of direct rain drops and acts as a barrier to surface flow and even holds together slope material. This situation over the mountain slope helps to develop grass cover area which will promote high canopy density and high vegetation density and finally will reduce surface run-off, soil erosion and slope failure. Such method could be very much applicable in the degenerated areas of Mirik Block and where structural measures are not possible enough due to very steep slope gradient and very fragile rock-soil composition.

\section{References}

Azizia A, Najafia Z, Sohrabia H (2008) Forest canopy density estimating, using satellite. The International Archives of the Photogrammetry, Remote Sensing and Spatial Information Sciences. Vol. XXXVII. Part B8. Beijing 2008

Banerjee K, Panda S, Bandyopadhyay J, Jain MK (2014) Forest canopy density mapping using advanced geospatial technique. Int Innov Sci Eng Technol 1(7):358-363

Boyd DS, Foody GM, Ripple WJ (2002) Evaluation of approaches for forest cover estimation in the Pacific Northwest, USA, using remote sensing. Appl Geogr 22:292-375

Caiyan WU, Jianping Q (2009) Relationship between landslides and lithology in the three gorges reservoir area based on GIS and information value model. Higher Education Press and Springer Verlag 4(2):165-170

Donati L, Turrini MC (2002) An objective and method to rank the importance of the factors predisposing to landslides with the GIS methodology, application to an area of the Apennines (Valnerina; Perugia, Italy). Eng Geol 63:277-289

Forest Survey of India (2000) State of Forest Report 1999. Forest Survey of India, New Delhi

Franklin J, Logan TL, Woodcock CE, Strahler AH (1986) Coniferous vegetation coverage classification and inventory using Landsat and digital terrain data. IEEE Trans Geosci Remote Sens GE 24(1):139-149

Guzzetti F, Carrara A, Cardinali M, Reichenbach P (1999) Landslide hazard evaluation: a review of current techniques and their application in a multi-scale study, Central Italy. J Geomorphol. Elsevier, London, 31:181-216

Hall FG, Townshend JR, Engman ET (1995) Status of remote sensing algorithms for estimation of land surface state parameters. Remote Sens Environ 51:138-156

Jennings SB, Brown ND, Sheil D (1999) Assessing forest canopies and understory illumination: canopy closure, canopy cover and other measures. Forestry 72:59-74

Jibson WR, Edwin LH, John AM (2000) A method for producing digital probabilistic seismic landslide hazard maps. Eng Geol 58:271-289

Joshi C, Leeuw JD, Skidmore AK, Duren ICV, Oosten HV (2006) Remotely sensed estimation of forest canopy density: a comparison of the performance of four methods. Int $\mathrm{J}$ Appl Earth Obs Geoinf 8(2):84-95

Lee S, Choi U (2003) Development of GIS based geological hazard information system and its application for landslide analysis in Korea. Geosci J 7:243-252

Lee S, Pradhan B (2007) Landslide hazard mapping at selangor, malaysia using frequency ratio and logistic regression models. Landslides J 4(1):33-41

Lee S, Ryu JH, Won JS, Park HJ (2004a) Determination and publication of the weights for landslide susceptibility mapping using an artificial neural network. Eng Geol 71:289-302

Lee S, Choi J, Min K (2004b) Probabilistic landslide hazard mapping using GIS and remote sensing data at Boun, Korea. Int J Remote Sens 25:2037-2052

Mickelson JG, Civco DL, Silander JA (1998) Delineating vegetation coverage canopy species in the northeastern United States using multi-temporal TM imagery. Photogramm Eng Remote Sens. 64(9):891-904

Mondal S, Maiti R (2011) Landslide susceptibility analysis of Shivkhola watershed, Darjiling: a remote sensing \& GIS Based Analytical Hierarchy Process (AHP). J Indian Soc Remote Sens. doi:10.10007/s12524-011-0160-9

Muthu K, Petrou M (2007) Landslide hazard mapping using an expert system and a GIS. Trans Geosci Remote Sens 45(2):522-531

Pandey A, Dabral PP, Chowdhary VM, Yadav NK (2008) Landslide hazard zonation using remote sensing and GIS: a case study of Dikrong River Basin, Arunachal Pradesh, India. Environ Geol 54:1517-1529

Pradhan B, Lee S (2010a) Delineation of landslide hazard areas on Penang Island, Malaysia, by using frequency ratio, logistic regression, and artificial neural network models. Environ Earth Sci 60:1037-1054

Pradhan B, Lee S (2010b) Regional landslide susceptibility analysis using back-propagation neural network model at Cameron Highland, Malaysia. Landslides 7(1):13-30

Rikimaru A (1996) Landsat TM data processing guide for forest canopy density mapping and monitoring model. ITTO workshop on utilization of remote sensing in site assessment and planning for rehabilitation of logged-over forest, Bangkok, Thailand, pp 1-8

Rikimaru A, Roy PS, Miyatake S (2002) Tropical forest cover density mapping. Trop Ecol 43:39-47

Rowbotham D, Dudycha DN (1998) GIS modelling of slope stability in Phewa Tal watershed, Nepal. Geomorphology 26:151-170

Saeijamalabad M, Abkar AA (2000) Vegetation coverage canopy density monitering, using satellite images. ISPRS Commission VII, 17, Amsterdam, Holland

Sarkar S, Kanungo DP (2004) An integrated approach for landslide susceptibility mapping using remote sensing and GIS. Photogramm Eng Remote Sens 70(5):617-625

Townshend JRG (1992) Land cover. Int J Remote Sens 13(6):1319-1328

Tucker CJ, Holben BN, Goff TE (1984) Intensive forest clearing in Rondonia, Brazil, as detected by satellite remote sensing. Remote Sens Environ 15:255-261

Vijith et al (2009) Using InfoVal method and GIS techniques for the spatial modelling of landslide susceptibility in the upper catchment of river Meenachil in Kerala. J Indian Soc Remote Sens 37:241-250

Vijith H, Madhu G (2008) Estimating potential landslide sites of an Upland Sub-watershed in Western Ghat's of Kerala (India) through frequency ratio and GIS. Environ Geol 55:1397-1405

Zhou CH, Lee CF, Li J, Xu ZW (2002) On the spatial relationship between landslide and causative factors on Lantau Island, Hong Kong. Geomorphology 43:197-207 